ORIGINAL ARTICLE / ARTIGO ORIGINAL

\title{
Who are the people with Alzheimer's disease in Brazil? Findings from the Brazilian Longitudinal Study of Aging
}

\author{
Quem são as pessoas com Doença de Alzheimer no Brasil? Resultados do \\ Estudo Longitudinal da Saúde dos Idosos Brasileiros (ELSI-Brasil)
}

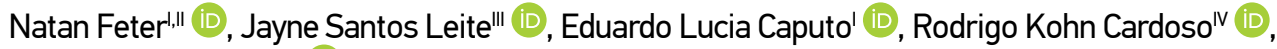 \\ Airton José Rombaldi' (iD)
}

\begin{abstract}
Objective: To describe the socioeconomic, behavioral, clinical, and health-related characteristics of Brazilian older adults with Alzheimer's disease (AD). Methods: Baseline data from the Brazilian Longitudinal Study of Aging were analyzed. This nationwide survey interviewed 9,412 adults aged at least 50 years. Selfreported medical diagnosis of $\mathrm{AD}$ and exposure variables (sociodemographic, clinical, behavioral, and healthrelated) were assessed by face-to-face questionnaire-based interview. Multivariate analyses accounted for possible confounding factors, and values were reported in prevalence ratio (PR) and $95 \%$ confidence interval (95\%CI). Results: Participants with AD have important demographic differences compared with older non-AD participants such as low education level and retirement. Clinically, these patients reported more medical appointments, falls, and higher frequency and duration of hospitalizations compared with non-AD participants. These characteristics may be related to worse physical and mental health observed in this population. Indeed, two out of five older adults with $\mathrm{AD}$ in Brazil reported always feeling lonely, while two out of three said they felt depressed or sad much of the time. Adjusted analyses showed that patients with AD were $95 \%(95 \% \mathrm{CI}$ $1.08-3.50)$ more likely to be hospitalized in a year compared with non-AD older adults. People with AD in Brazil were more likely to be diagnosed with diabetes ( $\mathrm{PR}=1.83[95 \% \mathrm{CI} 1.08-3.12])$, depression $(\mathrm{PR}=3.07 \%$ [95\%CI $1.63-5.79])$, Parkinson's disease ( $\mathrm{PR}=17.63$ [95\%CI $6.99-44.51])$, and stroke (PR $=3.55$ [95\%CI 1.90 - 6.67]) compared with non-AD participants. Conclusion: Older adults with AD in Brazil reported impaired physical and mental health compared with the non-AD population.
\end{abstract}

Keywords: Alzheimer disease. Aged. Cohort studies. Brazil.

ISuperior School of Physical Education, Universidade Federal de Pelotas - Pelotas (RS), Brazil.

"School of Human Movement and Nutrition Sciences, University of Queensland - Brisbane (Qld), Australia.

"'Graduate Program in Cardiology, Medicine School, Universidade Federal do Rio Grande do Sul - Porto Alegre (RS), Brazil.

IvColégio Militar de Porto Alegre - Porto Alegre (RS), Brazil.

Corresponding author: Natan Feter. Centre for Research on Exercise, Physical Activity and Health, School of Human Movement and Nutrition Sciences, University of Queensland, 4072, Brisbane, Australia. E-mail: natanfeter@hotmail.com

Conflict of interests: nothing to declare - Financial support: Coordenação de Aperfeiçoamento de Pessoal de Nível Superior - Brasil (CAPES) - Finance Code 001, Brazilian Ministry of Health, Health Care Secretariat, and Ministry of Science, Technology, Innovation and Communication. 
RESUMO: Objetivo: Descrever as características socioeconômicas, comportamentais, clínicas e aquelas relacionadas à saúde de idosos brasileiros com Doença de Alzheimer (DA). Métodos: Foram analisados dados de linha de base do Estudo Longitudinal da Saúde dos Idosos Brasileiros (ELSI-Brasil). Essa pesquisa nacional entrevistou 9.412 adultos com pelo menos 50 anos. O diagnóstico de DA e as variáveis de exposição (sociodemográficas, clínicas, comportamentais e aquelas relacionadas à saúde) foram avaliados por meio de entrevista face a face baseada em questionário. As análises multivariadas foram ajustadas por possíveis fatores de confusão, e os valores foram relatados na razão de prevalência (RP) e intervalo de confiança de 95\% (IC95\%). Resultados: Participantes com DA apresentam diferenças demográficas significativas em comparação com idosos sem DA, como aposentadoria e baixa escolaridade. Os respondentes relataram mais consultas médicas, quedas, e maior frequência e duração de hospitalizações quando comparado a participantes sem DA. Essas características podem estar relacionadas à pior saúde física e mental observada nessa população. Dois em cada três idosos com DA no Brasil relataram que se sentiam deprimidos ou tristes na maior parte do tempo. As análises ajustadas revelaram que os pacientes com DA tinham maior probabilidade de serem diagnosticados com diabetes $[\mathrm{PR}=1,83$ (IC95\% 1,08 - 3,12)], depressão $[\mathrm{PR}=$ 3,07\% (IC95\% 1,63 - 5,79)], doença de Parkinson [PR = 17,63 (IC95\% 6,99 - 44,51)], e acidente vascular cerebral $[\mathrm{PR}=3,55$ (IC95\% 1,90 - 6,67)] em comparação com adultos mais velhos sem diagnóstico de DA. Conclusão: Idosos com DA no Brasil relataram problemas de saúde física e mental em comparação com a população idosa sem DA.

Palavras-chave: Doença de Alzheimer. Idoso. Estudos de coortes. Brasil.

\section{INTRODUCTION}

In 2016 Brazil presented the second-highest age-standardized prevalence of dementia in the world ${ }^{1}$, with Alzheimer's disease (AD) accounting for about $70 \%$ of cases $^{2}$. From 2007 to 2017 , the number of deaths due to dementia in the country increased in $55.5 \%$, which is more than breast, prostate, and liver cancer deaths combined ${ }^{3}$. High prevalence and mortality rate have led to an increased burden of AD in the Brazilian hospital system. According to the Brazilian Ministry of Health ${ }^{4}$, the number of hospitalizations due to AD and their total economic cost increased 88 and $44 \%$, respectively, from 2010 to 2019 . For comparison purposes, hospitalizations from cerebrovascular and ischemic heart disease increased 36.3 and $29.3 \%$, respectively, during the same period.

In addition to cognitive and behavioral symptoms and loss of functional capacity, other factors may be associated with the increased burden of AD for patients and their families such as high presence of comorbidities ${ }^{5-7}$, impaired access to healthcare facilities ${ }^{8}$, and unhealthy lifestyle 9 . In this sense, Brazil has made important advances in the development and implementation of healthcare programs and policies focusing on mental and physical health of the older adult population to reduce the social and economic burden of $\mathrm{AD}^{10}$. In 2020, the first step to create the National Policy on AD and other dementias was completed in the Federal Senate of Brazil ${ }^{11}$. Similar to what is observed in other countries, this document aims to improve the prevention and care of people with $\mathrm{AD}$ as well as to raise awareness of this disease. 
However, the lack of national perspective on social, economic, and clinical factors among people with AD in Brazil lead to disparities in access, coverage, and treatment ${ }^{12}$. For example, a recent systematic review showed that, from seven studies that identified the prevalence of clinically-assessed dementia among older adults in Brazil, six were conducted in the Southeast (states of São Paulo and Minas Gerais) and one in the Northeast (state of Bahia) regions $^{13}$. Then, the objective of this study was to describe the socioeconomic, behavioral, clinical, and health-related characteristics of people with AD in Brazil.

\section{METHODS}

\section{STUDY DESIGN}

This descriptive study analyzed baseline data from the Brazilian Longitudinal Study of Aging (ELSI-Brazil). This longitudinal home-based survey was conducted in 2015 and 2016 with a nationally representative sample of adults aged 50 years or older in Brazil ${ }^{14}$. Data were collected by face-to-face questionnaire-based interviews and physical measurements (e.g., weight, height). Interviewers were trained and certificated according to the study protocol ${ }^{14}$. Further, as a quality assurance and control strategy, interviews were recorded, if authorized by the respondent, to be reviewed by trained supervisors.

A series of pilot studies were performed to identify and correct potential problems in the data collection instruments and procedures. The standardized study procedures are detailed in the ELSI-Brazil operations manual (available at the ELSI-Brazil homepage: http://elsi.cpqrr.fiocruz.br/). The ELSI-Brazil was approved by the Ethics Committee of the René Rachou Research Center of Oswald Cruz Foundation. More details on survey methods, data collection, and study design can be found elsewhere ${ }^{14}$. The full household and individual questionnaires are available from the ELSI-Brazil homepage (http: / / elsi.cpqrr.fiocruz.br/).

\section{SAMPLE}

The sample size was estimated in 10,000 older adults (9,412 participated in the study). Sampling design was conducted with selection stages in order to obtain a representative sample of the noninstitutionalized population within the eligible age range (i.e., 50 years or older) and also from municipalities of different population size. Primary sampling units consisted in municipalities that were allocated to four strata based on population size. Then, eight census tracts were selected in each municipality in the second stage. In the third and last selection stage, households were selected from each census tracts. Then, sample weight was obtained to account for nonresponses and geographic stratification, in such a way population-based inference was possible ${ }^{14}$. All residents aged 50 or older were eligible for individual interview. 


\section{OUTCOME VARIABLE}

To measure the number of diagnosed cases of AD among older adults in Brazil, the following question was used: "Has a doctor ever told you that you have Alzheimer's disease?". If the participant was not able to take part of the interview for any reason (i.e., cognitive impairment), a family member or caregiver answered it.

\section{DEMOGRAPHIC VARIABLES}

The authors used information about age (years), sex (men/women), education (no formal education, elementary, high school, or higher), ethnicity (white, mixed-race, other), marital status (married, singled, separated or divorced, widowed), total annual income (quintile), occupation (employed, unemployed, retired) and, if applicable, reason for being retired (age, time of service, disability, other).

\section{CLINICAL VARIABLES}

Information related to health insurance, frequency of appointments with general physician (GP) or dentist, incidence and duration (none, one week or less, more than one week) of hospitalization, screening services (mammography and eye examination), and incidence of falls were also assessed.

\section{BEHAVIORAL, NUTRITIONAL, AND HEALTH-RELATED VARIABLES}

Interviewers also accessed self-perception of general health (very good or good, fair, poor or very poor), hearing, and vision (excellent to good, regular, bad to very bad). Functional capacity was examined by interviewers at the respondent's home. The 3-meter walking test ${ }^{15}$ (tertile) and questionnaire about functional impairment (impairment in none, one or two, or three or more activities of daily living - ADL) were performed. Further, the survey also examined social interaction (participation in social events), quality of life based on the Quality of Life Scale (CASP-19 ${ }^{16}$ ) score, frequency of sadness and happiness based on 8-item Center for Epidemiologic Studies-Depression Scale (CES-D- $8^{17}$ ), and sleep quality (very good to good, regular, bad to very bad). Use of drugs to sleep was assessed. More information about each test can be found in the article concerning the ELSI protocol ${ }^{14}$.

Physical measurements were performed in duplicate at the participants' residences. Weight and height were assessed to obtain body mass index (BMI [normal, overweight, obese]). Waist circumference was reported based on the cutoff proposed by the World Health Organization $\left(102 \mathrm{~cm}\right.$ or higher for men and $88 \mathrm{~cm}$ or higher for women $\left.{ }^{18}\right)$. In addition, 
leisure-time physical activity (measured by the International Physical Activity Questionnaire ${ }^{19}$ ), awareness of public program to practice physical activity, smoking habit (never, former smoker, current smoker), presence of diagnosed hypertension, diabetes, depression, stroke, and Parkinson's disease were investigated.

Leisure-time physical activity was further categorized in active, insufficiently active, and inactive, based on the World Health Organization guideline ${ }^{20}$ (active: at least 150 minutes of moderate-to-vigorous physical activity per week; insufficiently active: between 149 and 1 minute per week; inactive: 0 minute per week).

\section{STATISTICAL ANALYSIS}

Data were imported into STATA 13.1 (StataCorp, College Station, Texas). All analyses were carried out using the "svy" command in order to consider the sample weights and expand the results for the Brazilian population aged 50 years or older. Descriptive data are presented as relative frequencies and $95 \%$ confidence interval $(95 \% \mathrm{CI})$. In order to compare proportions between groups, Chi-squared and Fisher's exact tests were used, as appropriate. When applicable, linear trend test was performed to identify linear associations between variables. Moreover, independent T-test was used to identify differences between groups in continuous variables (i.e., age in years).

In multivariable analysis, Poisson regression was performed to identify the probability of AD participants present the exposure variables compared with non-AD participants. A p-value $\leq 0.20$ in bivariate analyses was assumed to include a variable on multivariable analyses. Then, a three-level hierarchical model was used ${ }^{21}$. In the first level, sex, age, ethnicity, marital status, education level, and occupation were included. The second level was composed of health insurance and falls. The third level included health status, walking test, quality of life, depression scale, body mass index, leisure-time physical activity, smoking habit, diabetes, and hypertension. The adopted level of significance was $\mathrm{p}<0.05$.

\section{RESULTS}

\section{SOCIODEMOGRAPHIC CHARACTERISTICS}

From a total of 9,412 individuals, $82(0.75 \%$; $95 \%$ CI $0.58-0.98)$ participants reported medical diagnosis of $\mathrm{AD}$, as shown in Supplementary Table $\mathrm{S} 1$. The prevalence was higher among participants aged between 70 and 79 years (1.67\% [95\%CI $1.11-2.50]), 80$ years or older $(4.56 \%$ [95\%CI $3.12-6.63])$, and widowed (1.88\% [95\%CI $1.26-2.80 \%$ ]). Self-or proxy-reported medical diagnosis of $\mathrm{AD}$ was more prevalent among older individuals, women $(67.9 \%)$, married (47.2\%), participants with elementary school only $(70.3 \%)$, and 
retired (84.8\%), as shown in Supplementary Table S2. Proxy interviews were conducted in $61 \%(n=50)$ of the participants. Table 1 illustrates the findings from the multivariable analysis. Participants with AD were more likely to be older, unemployed or retired, and less likely to be black. In addition, participants who completed elementary school or had lower educational attainment were more likely to report medical diagnosis of AD.

\section{HEALTH SYSTEM COVERAGE}

As shown in Supplementary Table S3, older adults with AD in Brazil have more appointments per year with GP compared with non-AD participants. On the other hand, people with $\mathrm{AD}$ have fewer visits to specialists (i.e., dentist and eye examination) and lower frequency of mammography among women than non-AD participants. Furthermore, people with AD have higher frequency of falls and hospitalizations, and longer hospital stays when compared with non-AD participants.

After adjusting for covariates, participants with $\mathrm{AD}$ were more likely to have 10 or more GP appointments in the last 12 months, and to have more hospital admissions and longer hospital stays in the same period compared with non-AD participants (Table 1). Furthermore, $\mathrm{AD}$ participants were more likely to have the latest eye examination and dentist appointment over 2 years before the survey.

\section{CLINICAL AND BEHAVIORAL CHARACTERISTICS}

Supplementary Table S4 reported that older adults with AD perceived their health, hearing, and long-distance vision worse than non-AD participants. In addition, about $70 \%$ of all AD participants were in the lowest tertile of walking test and $64.8 \%$ reported some impairment in at least one instrumental activity of daily living. There was no difference between groups in short-distance vision, social activity, quality of life, CESD-8 score, sleep quality, BMI, knowledge of public program of physical activity promotion, and smoking habit.

A total of $41 \%$ of AD participants reported always feeling lonely (Supplementary Table S3). Similarly, 65 and $68.2 \%$ said they felt depressed and sad most of the time, respectively. Moreover, the proportion of AD participants who reported feeling happy much of the time was lower than non-AD participants. The proportion of older adults with AD using drug for sleep, high waist circumference, physically inactive, diagnosed hypertension, diabetes, and depression was higher than the non-AD group.

Table 2 describes the multivariable analysis among clinical characteristics according to self- or proxy-reported medical diagnosis of $A D$ in Brazil. As expected, people with AD were more likely to report impairment in three or more activities of daily living (PR [prevalence ratio $]=10.59[95 \% \mathrm{CI} 4.43-25.25])$. Furthermore, these patients were 2.75 (95CI\% $1.13-6.67)$ times more likely to feel sad much of the time, and hence they were less likely 
Table 1. Analyses of sociodemographic characteristics from adults diagnosed with Alzheimer's disease in Brazil, $2015(n=9,412)$.

\begin{tabular}{|c|c|c|c|c|c|c|}
\hline & \multicolumn{3}{|c|}{ Crude } & \multicolumn{3}{|c|}{ Adjusted* } \\
\hline & PR & $95 \% \mathrm{Cl}$ & p-value & PR & $95 \% \mathrm{Cl}$ & $\mathrm{p}$-value \\
\hline Women (ref: men) & 1.80 & $1.05-3.08$ & $0.031^{a}$ & 1.02 & $0.54-1.94$ & $0.956^{\mathrm{a}}$ \\
\hline Age, years & 1.12 & $1.10-1.14$ & $<0.001^{\mathrm{b}}$ & 1.11 & $1.08-1.15$ & $<0.001^{b}$ \\
\hline \multicolumn{7}{|l|}{ Ethnicity (ref: white) } \\
\hline Mixed-race & 1.07 & $0.62-1.84$ & \multirow{3}{*}{$0.117^{a}$} & 1.70 & $0.93-3.02$ & \multirow{3}{*}{$0.007^{a}$} \\
\hline Black & 0.30 & $0.08-1.14$ & & 0.08 & $0.01-0.64$ & \\
\hline Asian & 0.21 & $0.03-1.54$ & & 0.41 & $0.06-3.56$ & \\
\hline \multicolumn{7}{|l|}{ Marital status (ref: single) } \\
\hline Married & 0.86 & $0.36-2.08$ & \multirow{3}{*}{$0.002^{\mathrm{a}}$} & 1.00 & $0.32-3.13$ & \multirow{3}{*}{$0.809^{a}$} \\
\hline Divorced/separated & 0.71 & $0.22-2.26$ & & 1.52 & $0.49-4.71$ & \\
\hline Widowed & 2.88 & $1.25-6.63$ & & 1.21 & $0.40-3.64$ & \\
\hline \multicolumn{7}{|c|}{ Education level (ref: high school or higher) } \\
\hline $\begin{array}{l}\text { Elementary school } \\
\text { or lower }\end{array}$ & 0.72 & $0.38-1.35$ & $<0.001^{\mathrm{b}}$ & 2.61 & $1.00-6.83$ & $0.531^{b}$ \\
\hline \multicolumn{7}{|l|}{ Occupation (ref: employed) } \\
\hline Unemployed & 27.09 & $4.00-183.61$ & \multirow{2}{*}{$<0.001^{\mathrm{a}}$} & 16.77 & $1.99-141.51$ & \multirow{2}{*}{$0.016^{\mathrm{a}}$} \\
\hline Retired & 91.81 & $12.89-654.03$ & & 21.44 & $2.95-155.72$ & \\
\hline Health insurance (ref: no) & 1.50 & $0.90-1.53$ & $0.121^{\mathrm{a}}$ & 1.02 & $0.60-1.72$ & $0.954^{\mathrm{a}}$ \\
\hline $\begin{array}{l}\geq 10 \text { medical visits in the last } \\
12 \text { months (ref: }<10 \text { visits) }\end{array}$ & 4.21 & $2.69-6.58$ & $<0.001^{b}$ & 3.19 & $1.76-5.79$ & $<0.001^{\mathrm{a}}$ \\
\hline $\begin{array}{l}\text { Hospitalized in the last } \\
12 \text { months (ref: no) }\end{array}$ & 3.39 & $2.19-5.23$ & $<0.001^{\mathrm{b}}$ & 1.95 & $1.08-3.50$ & $0.026^{b}$ \\
\hline $\begin{array}{l}\text { Fall in the last } 12 \text { months } \\
\text { (ref: no) }\end{array}$ & 2.16 & $1.28-3.65$ & $0.004^{b}$ & 1.34 & $0.68-2.64$ & $0.399^{b}$ \\
\hline $\begin{array}{l}\text { Hospitalization longer } \\
\text { than one week } \\
\text { (ref: one week or less) }\end{array}$ & 5.42 & $2.23-13.19$ & $<0.001^{\mathrm{b}}$ & 2.27 & $0.87-5.92$ & $0.046^{b}$ \\
\hline $\begin{array}{l}\text { Last dentist visit } \\
\text { (ref: <2 years ago) }\end{array}$ & 1.80 & $1.44-2.26$ & $<0.001^{\mathrm{a}}$ & 1.90 & $1.06-3.42$ & $0.031^{a}$ \\
\hline $\begin{array}{l}\text { Looked for any medical } \\
\text { service in the last } 2 \\
\text { weeks (ref: no) }\end{array}$ & 4.21 & $2.69-6.58$ & $<0.001^{\mathrm{b}}$ & 1.44 & $0.75-2.79$ & $0.272^{\mathrm{a}}$ \\
\hline $\begin{array}{l}\text { Last mammography } \\
\text { exam (ref: < } 3 \text { years ago) }\end{array}$ & 2.68 & $1.49-4.83$ & $0.001^{a}$ & 0.98 & $0.47-2.05$ & $0.963^{a}$ \\
\hline $\begin{array}{l}\text { Last eye exam } \\
\text { (ref: }<2 \text { years ago) }\end{array}$ & 1.28 & $1.07-1.53$ & $0.007^{a}$ & 1.24 & $1.05-1.46$ & $0.012^{\mathrm{a}}$ \\
\hline
\end{tabular}

PR: prevalence ratio; 95\% Cl: 95\% confidence interval; ref: reference; aheterogeneity test; blinear trend test; *adjusted for sex, age, ethnicity, marital status, education level, occupation, health insurance, and fall. 
Table 2. Crude and adjusted analyses among clinical characteristics according to self-reported medical diagnosis of Alzheimer's disease in Brazil, $2015(n=9,412)$.

\begin{tabular}{|c|c|c|c|c|c|c|}
\hline & \multicolumn{3}{|c|}{ Crude } & \multicolumn{3}{|c|}{ Adjusted* $^{*}$} \\
\hline & PR & $95 \% \mathrm{Cl}$ & p-value & PR & $95 \% \mathrm{Cl}$ & p-value \\
\hline \multicolumn{7}{|c|}{ Health status (ref: Very good/good) } \\
\hline Fair & 1.03 & $0.54-1.98$ & \multirow{2}{*}{$0.056^{b}$} & 1.20 & $0.55-2.63$ & \multirow{2}{*}{$0.117^{b}$} \\
\hline Poor/very poor & 3.00 & $1.52-5.94$ & & 2.61 & $1.21-5.64$ & \\
\hline \multicolumn{7}{|c|}{ Self-rated hearing (ref: excellent/good) } \\
\hline Regular & 1.39 & $0.77-2.54$ & \multirow{2}{*}{$<0.001^{b}$} & 0.72 & $0.32-1.64$ & \multirow{2}{*}{$0.200^{\mathrm{b}}$} \\
\hline Bad - very bad & 7.31 & $3.75-14.25$ & & 2.45 & $0.95-6.30$ & \\
\hline \multicolumn{7}{|c|}{ Self-rated long-distance vision (ref: excellent/good) } \\
\hline Regular & 1.93 & $1.0-3.76$ & \multirow{2}{*}{$<0.001^{b}$} & 1.06 & $0.49-2.33$ & \multirow{2}{*}{$0.153^{b}$} \\
\hline Bad - very bad & 3.64 & $2.05-6.46$ & & 1.87 & $0.87-4.02$ & \\
\hline \multicolumn{7}{|c|}{ Walking test, tertile (ref: $1^{\text {st }}$ and $2^{\text {nd }}$ tertile) ${ }^{\mathrm{d}}$} \\
\hline $3^{\text {rd }}$ (slowest) & 3.97 & $1.67-9.44$ & $0.002^{b}$ & 0.86 & $0.28-2.65$ & $0.875^{b}$ \\
\hline \multicolumn{7}{|l|}{ Impaired ADL (ref: less than 3) } \\
\hline 3 or more & 23.75 & $13.22-42.67$ & $<0.001^{\mathrm{b}}$ & 10.59 & $4.43-25.25$ & $<0.001^{\mathrm{b}}$ \\
\hline \multicolumn{7}{|l|}{ Quality of life (ref: $1^{\text {st }}[$ lowest]) } \\
\hline $2^{\text {nd }}$ & 0.42 & $0.14-1.19$ & \multirow{2}{*}{$0.103^{b}$} & 0.50 & $0.14-1.72$ & \multirow{2}{*}{$0.438^{b}$} \\
\hline $3^{\text {rd }}$ (highest) & 0.34 & $0.08-1.43$ & & 0.60 & $0.15-2.68$ & \\
\hline $\begin{array}{l}\text { Elevated depression } \\
\text { symptoms (ref: no) }\end{array}$ & 2.01 & $0.69-5.91$ & $0.202^{b}$ & 2.61 & $0.88-7.79$ & $0.085^{a}$ \\
\hline Happy most of the time (ref: no) & 0.46 & $0.22-0.95$ & $0.036^{\mathrm{a}}$ & 0.41 & $0.15-1.09$ & $0.073^{\mathrm{a}}$ \\
\hline Sad most of the time (ref: no) & 3.66 & $1.76-7.61$ & $0.001^{a}$ & 2.75 & $1.13-6.67$ & $0.026^{a}$ \\
\hline \multicolumn{7}{|c|}{ Feel lonely (ref: sometimes or never) } \\
\hline Always & 4.77 & $1.74-13.07$ & $0.005^{\mathrm{b}}$ & 2.52 & $0.73-8.67$ & $0.158^{b}$ \\
\hline Central obesity (ref: no) & 1.86 & $1.15-3.00$ & $0.012^{\mathrm{a}}$ & 1.23 & $0.67-2.23$ & $0.505^{a}$ \\
\hline \multicolumn{7}{|l|}{ Physical activity (ref: inactive) } \\
\hline Insufficiently active & 0.33 & $0.17-0.64$ & \multirow{2}{*}{$<0.001^{b}$} & 0.41 & $0.14-1.21$ & \multirow{2}{*}{$0.242^{b}$} \\
\hline Active & 0.29 & $0.14-0.59$ & & 0.59 & $0.23-1.53$ & \\
\hline \multicolumn{7}{|l|}{ Smoking habit (ref: never) } \\
\hline Former smoker & 0.78 & $0.44-1.37$ & \multirow{2}{*}{$0.120^{a}$} & 0.75 & $0.38-1.49$ & \multirow{2}{*}{$0.348^{\mathrm{a}}$} \\
\hline Smoker & 0.39 & $0.16-0.98$ & & 0.81 & $0.27-2.39$ & \\
\hline \multicolumn{7}{|c|}{ Sleep quality (ref: very good/good) } \\
\hline Regular & 1.19 & $0.64-2.18$ & \multirow{2}{*}{$0.363^{b}$} & 1.16 & $0.57-2.36$ & \multirow{2}{*}{$0.675^{b}$} \\
\hline Bad/very bad & 1.57 & $0.84-2.96$ & & 1.17 & $0.47-2.96$ & \\
\hline Drugs for sleep (ref: no) & 3.78 & $2.19-6.55$ & $<0.001^{\mathrm{a}}$ & 2.54 & $1.29-5.01$ & $0.007^{a}$ \\
\hline Hypertension (ref: no) & 1.91 & $1.08-3.38$ & $0.026^{a}$ & 1.30 & $0.71-2.39$ & $0.390^{\mathrm{a}}$ \\
\hline Diabetes (ref: no) & 2.41 & $1.38-4.22$ & $0.002^{\mathrm{a}}$ & 1.83 & $1.08-3.12$ & $0.040^{\mathrm{a}}$ \\
\hline Diagnosed depression (ref: no) & 3.57 & $2.18-5.86$ & $<0.001^{\mathrm{a}}$ & 3.07 & $1.63-5.79$ & $0.001^{a}$ \\
\hline Parkinson's disease (ref: no) & 21.41 & $11.20-40.92$ & $<0.001^{\mathrm{a}}$ & 17.63 & $6.99-44.51$ & $<0.001^{\mathrm{a}}$ \\
\hline Stroke (ref: no) & 6.37 & $3.94-10.29$ & $<0.001^{\mathrm{a}}$ & 3.55 & $1.90-6.67$ & $<0.001^{\mathrm{a}}$ \\
\hline
\end{tabular}

PR: prevalence ratio; $95 \% \mathrm{Cl}$ : 95\% confidence interval; ADL: Activities of daily living; ref: reference; aheterogeneity test; ${ }^{b}$ linear trend test; ' only among women; 'lower score indicates high functional impairment; 'score higher than 4 in the 8-item CES-D; *adjusted for sex, age, ethnicity, marital status, education level, occupation, health insurance, and fall. 
to feel happy most of the time, although this association did not reach statistical significance $(\mathrm{PR}=0.41[95 \% \mathrm{CI} 0.15-1.09] ; \mathrm{p}=0.075)$. Participants with $\mathrm{AD}$ had no increased likelihood to worse sleep quality although they were more likely to use drugs for sleep $(\mathrm{PR}=$ 2.54 [95\%CI $1.29-5.01]$ ). In addition, these participants were more likely to be diagnosed with diabetes $(\mathrm{PR}=1.83$ [95\%CI 1.08-3.12]), depression ( $\mathrm{PR}=3.07$ [95\%CI $1.63-5.79])$, Parkinson's disease $(\mathrm{PR}=17.63$ [95\%CI $6.99-44.51])$, and stroke $(\mathrm{PR}=3.55$ [95\%CI $1.90-$ 6.67]) compared with non-AD participants.

\section{DISCUSSION}

This is the first study that described the socioeconomic, clinical, behavioral, and health-related characteristics of people with AD in Brazil. The authors highlighted that older adults with $\mathrm{AD}$ are less likely to be black and more likely to be retired or unemployed. Moreover, these participants are more likely to have more GP visits and hospitalizations during a oneyear period. On the other hand, they are less likely to do regular eye examination and visit a dentist. These findings showed that older adults with $\mathrm{AD}$ in Brazil reported poor mental health with higher likelihood of feeling sad and being diagnosed with other chronic condition such as depression and Parkinson's disease.

The observed prevalence of $\mathrm{AD}$ in the present study $(0.75 \%$ [95\%CI $0.58-0.98])$ was similar to the prevalence reported by the Institute for Health Metrics and Evaluation $(0.75 \%$ [0.65 - 0.85]) in Brazil in 20153. Furthermore, the proportion of people with AD in Brazil increased $127 \%$ since 1990 (0.33 [95\%CI $0.28-0.38$ ]). Other studies have explained that ageing is the most important risk factor for $\mathrm{AD}^{22}$. According to the Brazilian Institute of Geography and Statistics (IBGE) ${ }^{23}$, the population aged 60 years or older will increase in $284.2 \%$ from 2000 to 2050 . In this study, the likelihood of medical diagnosis of AD among the sample increases $11 \%(95 \%$ CI $8-15)$ for each year increased in ageing.

On the other hand, black participants have lower likelihood of reporting medical diagnosis of $\mathrm{AD}$ than whites. Racial inequalities in life expectancy ${ }^{24}$ and healthcare system access ${ }^{25,26}$ in Brazil may partly explain the lower likelihood for AD among black participants. Also, some authors explained that the word used for "Black" in Brazil — "preto" - might be used as a racial slur. This factor might lead some black people not to declare other individuals or even themselves as black ${ }^{27}$. However, the proportion of individuals self- or proxy-declared as black was similar to the observed in the latest national survey (continuum PNAD 2019) ${ }^{28}$. The 2020 report of the Lancet Commission showed that racial disparity is still one factor to be tackling in the management of $\mathrm{AD}$ and other dementias. Providing equal access to healthcare facilities is one way to reduce racial inequality in the burden of AD and other dementias.

The lack of regular screening, such as eye examination and dentist visits, must be highlighted. The reduced physical function and impaired activities of daily living with the disease progression may diminish the ability to adequate oral hygiene care ${ }^{29}$. Consequently, adequate access for maintenance of good oral health must be provided for patients with AD 
in Brazil. In an extended literature review, Kocaelli et al. ${ }^{30}$ reinforced that dental treatment, especially for patients with $\mathrm{AD}$, represents less pain, more dignity, and a better quality of life. Besides, lower frequency of eye examinations seems to be associated with an increased prevalence of vision problems in this population ${ }^{31}$. Similar to oral health, adequate access to visual treatment means not only an optimal visual function, but also a better quality of life.

$\mathrm{AD}$ is characterized by a decline in cognitive and physical capacity leading to fragility and inability to independently perform daily activities. Previous findings have proposed gait speed, an index of functional capacity, as an independent predictor of mortality in older adults $^{32,33}$. As expected, people with AD were more likely to report impairment in three or more activities of daily living ${ }^{34}$. Strictly associated with independence and functional capacity, vision and hearing impairments were also highly prevalent in this population. However, there is no consistent positive effect of interventions, such as provision of hearing aids, prism lens, and cataract surgery, in cognitive decline and caregivers' burden of people with $\mathrm{AD}^{35}$. Therefore, patients must be stimulated to perform physical and social activity in a daily basis as a non-pharmacological approach to preserve or even improve functional capacity and quality of life. Reducing the degree of dependence from caregivers is a reachable goal that results in a reduced burden of $\mathrm{AD}$ for the patient, caregivers, and the family.

Furthermore, presence of comorbidities, such as cardiovascular and metabolic diseases ${ }^{5}$, might be associated with the high rate of hospital admissions in older adults with AD. The 2020 report of the Lancet Commission ${ }^{36}$ highlighted the need for holistic post-diagnostic care, as most people with $\mathrm{AD}$ and other dementias have other illnesses and might struggle to correctly manage them. The correct management of chronic diseases might reduce the occurrence of potentially preventable hospitalizations. For example, diabetes-related complications increase in 2.25 and 1.61 the likelihood for potentially avoidable hospitalization in individuals with $\mathrm{AD}^{7}$. Likewise, in the United States of America, falls and ischemic heart disease are the main causes of hospitalizations among AD patients ${ }^{6}$. Impaired physical capacity has been described as risk factor for mortality ${ }^{37}$, poor quality of life $^{38}$, and increased economic cost ${ }^{39}$. Although its cause has not been completely understood, decline in physical capacity have been linked to low level of physical activity and increased sitting time ${ }^{9}$. Thus, it is worth highlighting the importance of increased awareness on these diseases not only as independent chronic diseases, but also in the biological and social relationship between them.

Some limitations of the present study must be acknowledged. First, its cross-sectional design does not allow the authors to propose any causal relationship between the assessed variables and medical diagnosis of AD. For example, the low likelihood of sleep problems in people with $\mathrm{AD}$ might be associated with the high proportion of participants who reported using drugs to sleep. However, this type of study design is essential to provide information for policymakers about the current needs of people with AD in Brazil.

Second, AD was assessed based on self- or proxy-report of physician diagnosis. In order to mitigate the effect of memory failures that could lead to misclassification bias, proxy interviews $(61 \%[\mathrm{n}=50])$ were conducted with a family member or caregivers if the participant was physically or cognitively impaired. ELSI-Brazil is part of the Health and Retirement 
Study (HRS) - Family Studies, covering around 150,000 older adults worldwide ${ }^{40}$. In all HRSFamily Studies, Alzheimer's disease was assessed with the same strategy (self- or proxy-reported medical diagnosis) in order to preserve comparability.

Third, 82 individuals reported medical diagnosis of $\mathrm{AD}$ in this survey. This low prevalence may be related to the under-detection rate of $77 \%$ in Brazil ${ }^{41}$. Nevertheless, the Brazilian National Survey of Health (Pesquisa Nacional de Saúde - PNS), conducted in 2013, was the largest survey in Brazil to monitor the health conditions and behaviors that included a question about dementia diagnosis. According to PNS, a prevalence of $0.60 \%$ (95\%CI $0.48-$ $0.73)$ of dementia was found, which is similar to that reported in the present study $(0.75 \%$; $95 \%$ CI 0.58 - 0.98). Indeed, the Institute for Health Metrics and Evaluation ${ }^{3}$ estimated a prevalence of $\mathrm{AD}$ and other dementia in Brazil in 0.75\% (0.65-0.85), which is close to the values reported in both ELSI and PNS. However, since PNS conducted in 2013 and ELSI, in 2015, no national-based survey with questions about dementia (i.e., AD) prevalence was conducted in the country with the second-highest age-standardized-prevalence of this syndrome. Prevalence data are mostly gathered from studies conducted in high-income countries $^{1}$ that may not have the best picture of how dementia impacts the public health system of a middle-income country such as Brazil.

The present study provides the first evidence, based on national survey, that people with AD in Brazil are more likely to have worse mental and physical health. People with $\mathrm{AD}$ in Brazil are underdiagnosed and undertreated, which may lead to higher frequency of medical visits, hospital admission, and comorbidities. The development of a universal and evidence-based agenda to preserve and improve the health of people with AD in Brazil is necessary to reduce the social and economic burden of this disease for the patients, their families, and society.

\section{REFERENCES}

1. GBD 2016 Dementia Collaborators. Global, regional, and national burden of Alzheimer's disease and other dementias, 1990-2016: a systematic analysis for the Global Burden of Disease Study 2016. Lancet Neurol 2019; 18(1): 88-106. https: / / doi.org/10.1016/ S1474-4422(18)30403-4

2. Alzheimer's Association. 2019 Alzheimer's disease facts and figures. Alzheimers Dement 2019; 15(3): 321-87. https:/ / doi.org/10.1016/j.jalz.2019.01.010

3. Institute for Health Metrics and Evaluation. GBD Results Tool [Internet]. University of Washington; 2019 [cited on Jan. 13, 2021]. Available from: http: / / ghdx.healthdata.org/gbd-results-tool

4. Brazil. Departamento de Informática do Sistema Único de Saúde--DATASUS. Brasilia. 2019;
5. Prince M, Wimo A, Guerchet M, Ali GC, Wu YT, Prina M. World Alzheimer Report 2015-The Global Impact of Dementia: An analysis of prevalence, incidence, cost and trends. 2015. London, Alzheimer's Dis Int 2017 ;

6. Alzheimer's Association. 2020 Alzheimer's disease facts and figures. Alzheimer's Dement [Internet] 2020;16(3):391-460 [cited on Nov. 4, 2020]. Available from: https: / / doi.org/10.1002/alz.12068

7. Desai U, Kirson NY, Ye W, Mehta NR, Wen J, Andrews JS. Trends in health service use and potentially avoidable hospitalizations before Alzheimer's disease diagnosis: A matched, retrospective study of US Medicare beneficiaries. Alzheimers Dement 2019; 11: 125-35. https: / / doi.org/ 10.1016\%2Fj.dadm.2018.12.005 
8. Durgante $\mathrm{H}$, Contreras $\mathrm{ML}$, Backhouse $\mathrm{T}$, Mavrodaris A, Ferreira MG, Paulo DLV, et al. Challenges in dementia care: comparing key issues from Brazil and the United Kingdom. Dement Neuropsychol 2020; 14(3): 216-22. https:// doi. org/10.1590/1980-57642020dn14-030003

9. Hartman YAW, Karssemeijer EGA, van Diepen LAM, Olde Rikkert MGM, Thijssen DHJ. Dementia Patients Are More Sedentary and Less Physically Active than Age- and Sex-Matched Cognitively Healthy Older Adults. Dement Geriatr Cogn Disord 2018; 46(1-2): 81-9. https:// doi.org/10.1159/000491995

10. Cieto BB, Valera GG, Soares GB, Cintra RH de $S$, Vale FAC. Dementia care in public health in Brazil and the world: A systematic review. Dement Neuropsychol 2014; 8(1): 40-6. https: / / doi.org/10.1590/ s1980-57642014dn81000007

11. Brasil. Senado Federal. Projeto de Lei $n^{\circ} 4.364$, de 2020 [Internet]. Brasil; 2020 [cited on Jan. 13, 2021]. Available from: https: / www25.senado.leg.br/web/ atividade/materias/-/materia/ 144381

12. Moraes FS de, Souza MLC de, Lucchetti G, Lucchetti ALG. Trends and disparities in the use of cholinesterase inhibitors to treat Alzheimer's disease dispensed by the Brazilian public health system-2008 to 2014: a nation-wide analysis. Arq Neuropsiquiatr 2018; 76(7): 444-51. https: / / doi.org/10.1590/0004-282x20180064

13. Farina N, Ibnidris A, Alladi S, Comas-Herreras A, Albanese E, Docrat S, et al. A systematic review and meta-analysis of dementia prevalence in seven developing countries: A STRiDE project. Glob Public Health 2020; 15(12): 1878-93. https:/ / doi.org/10.108 $0 / 17441692.2020 .1792527$

14. Lima-Costa MF, de Andrade FB, Souza Jr. PRB de, Neri AL, Duarte YAO, Castro-Costa E, et al. The Brazilian longitudinal study of aging (ELSI-BRAZIL): objectives and design. Am J Epidemiol 2018; 187(7): 1345-53. https: / / doi.org/10.1093/aje/kwx387

15. Lyons JG, Heeren T, Stuver SO, Fredman L. Assessing the agreement between 3-meter and 6-meter walk tests in 136 community-dwelling older adults. J Aging Health 2015; 27(4): 594-605. https:// dx.doi. org/10.1177\%2F0898264314556987

16. Hyde M, Wiggins RD, Higgs P, Blane DB. A measure of quality of life in early old age: the theory, development and properties of a needs satisfaction model (CASP19). Aging Ment Health 2003; 7(3): 186-94. https:// doi.org/10.1080/1360786031000101157

17. Turvey CL, Wallace RB, Herzog R. A revised CES-D measure of depressive symptoms and a DSM-based measure of major depressive episodes in the elderly. Int Psychogeriatr 1999; 11(2): 139-48. https: / / doi. org/10.1017/s1041610299005694
18. World Health Organization (WHO). Global action plan for the prevention and control of noncommunicable diseases 2013-2020. Geneva: World Health Organization; 2013.

19. Craig CL, Marshall AL, Sjöström M, Bauman AE, Booth ML, Ainsworth BE, et al. International physical activity questionnaire: 12 -country reliability and validity. Med Sci Sport Exerc 2003; 35(8): 1381-95. https: / / doi. org/10.1249/01.mss.0000078924.61453.fb

20. World Health Organization (WHO). Global recommendations on Physical Activity for health. Geneva: World Health Organization; 2010.

21. Victora CG, Huttly SR, Fuchs SC, Olinto MT. The role of conceptual frameworks in epidemiological analysis: a hierarchical approach. Int J Epidemiol 1997; 26(1): 224-7. https: / / doi.org/10.1093/ije/26.1.224

22. Hou Y, Dan X, Babbar M, Wei Y, Hasselbalch SG, Croteau $\mathrm{DL}$, et al. Ageing as a risk factor for neurodegenerative disease. Nat Rev Neurol 2019; 15(10): 565-81. https: / / doi.org/10.1038/s41582-019-0244-7

23. Instituto Brasileiro de Geografia e Estatística (IBGE). Censo demográfico 2010 [Internet]. Brasil: Instituto Brasileiro de Geografia e Estatística; 2010 [cited on Oct. 3, 2020]. Available from: https:// censo2010. ibge.gov.br/

24. Chiavegatto Filho ADP, Beltrán-Sánchez H, Kawachi I. Racial disparities in life expectancy in Brazil: challenges from a multiracial society. Am J Public Health 2014; 104(11): 2156-62. https:// doi.org/10.2105/ ajph.2013.301565

25. Chor D. Desigualdades em saúde no Brasil: é preciso ter raça. Cad Saúde Pública 2013; 29(7): 1272-5. https: / / doi.org/10.1590/S0102-311X2013000700002

26. Boccolini CS, Souza Junior PRB. Inequities in healthcare utilization: results of the Brazilian National Health Survey, 2013. Int J Equity Health 2016; 15(1): 150. https:/ / doi.org/10.1186/s12939-016-0444-3

27. Marteleto LJ. Educational inequality by race in Brazil, 1982-2007: structural changes and shifts in racial classification. Demography 2012; 49(1): 337-58. https: / / dx.doi.org/10.1007\%2Fs13524-011-0084-6

28. Instituto Brasileiro de Geografia e Estatística (IBGE). Continuous National Household Sample Survey Continuous PNAD [Internet]. Brasil: Instituto Brasileiro de Geografia e Estatística; 2020 [cited on Mar. 10, 2020]. Available from: https: / www.ibge.gov.br/en/ statistics/social/labor/16833-monthly-disseminationpnadc1.html? $=\& \mathrm{t}=\mathrm{o}$-que-e

29. Friedlander AH, Norman DC, Mahler ME, Norman KM, Yagiela JA. Alzheimer's disease: Psychopathology, medical management and dental implications. J Am Dent Assoc 2006; 137(9): 1240-51. https:// doi. org/10.14219/jada.archive.2006.0381 
30. Kocaelli H, Yaltirik M, Yargic LI, Özbas H. Alzheimer's disease and dental management. Oral Surg Oral Med Oral Pathol Oral Radiol Endod 2002; 93(5): 521-4. https: / / doi.org/10.1067/moe.2002.123538

31. Mendez MF, Tomsak RL, Remler B. Disorders of the visual system in Alzheimer's disease. J Clin Neuroophthalmol 1990; 10(1): 62-9.

32. Afilalo J, Eisenberg MJ, Morin J-F, Bergman H, Monette J, Noiseux N, et al. Gait speed as an incremental predictor of mortality and major morbidity in elderly patients undergoing cardiac surgery. J Am Coll Cardiol 2010; 56(20): 1668-76. https://doi.org/10.1016/j. jacc.2010.06.039

33. Chainani V, Shaharyar S, Dave K, Choksi V, Ravindranathan S, Hanno R, et al. Objective measures of the frailty syndrome (hand grip strength and gait speed) and cardiovascular mortality: A systematic review. Int J Cardiol 2016; 215: 487-93. https:/ / doi. org/10.1016/j.ijcard.2016.04.068

34. American Psychiatric Association. Diagnostic and Statistical Manual of Mental Disorders, Foruth Edition (DSM-IV). Washington, D.C.: American Psychiatric Association; 2004.

35. Dawes P, Wolski L, Himmelsbach I, Regan J, Leroi I. Interventions for hearing and vision impairment to improve outcomes for people with dementia: a scoping review. Int Psychogeriatr 2019; 31(2): 203-21. https: / / doi.org/10.1017/s1041610218000728

36. Livingston G, Huntley J, Sommerlad A, Ames D, Ballard C, Banerjee S, et al. Dementia prevention, intervention, and care: 2020 report of the Lancet Commission. Lancet 2020; 396(10248): 413-46. https: / / doi.org/10.1016/s0140-6736(20)30367-6
37. Newcomer R, Covinsky KE, Clay T, Yaffe K. Predicting 12-month mortality for persons with dementia. J Gerontol B Psychol Sci Soc Sci 2003; 58(3): S187-98. https:/ / doi.org/10.1093/geronb/58.3.s187

38. Wlodarczyk JH, Brodaty H, Hawthorne G. The relationship between quality of life, Mini-Mental State Examination, and the Instrumental Activities of Daily Living in patients with Alzheimer's disease. Arch Gerontol Geriatr 2004; 39(1): 25-33. https: / / doi. org/10.1016/j.archger.2003.12.004

39. Taylor Jr. DH, Schenkman M, Zhou J, Sloan FA. The relative effect of Alzheimer's disease and related dementias, disability, and comorbidities on cost of care for elderly persons. J Gerontol B Psychol Sci Soc Sci 2001; 56(5): S285-93. https://doi.org/10.1093/ geronb/56.5.s285

40. Program on Global Aging, Health and Policy. Gateway To Global Aging Data [Internet]. Program on Global Aging, Health and Policy; 2021 [cited on Jan. 13, 2021]. Available from: https://g2aging.org/

41. Nakamura AE, Opaleye D, Tani G, Ferri CP. Dementia underdiagnosis in Brazil. Lancet 2015; 385(9966): 4189. https: / / doi.org/10.1016/S0140-6736(15)60153-2

\section{Received on: 11/05/2020 \\ Revised on: 01/19/2021 \\ Accepted on: 01/20/2021}

Authors' contributions: NF and JSL conceived the concept and design of the study, NF participated in data analysis, JSL, ELC, RKC, and AJR provided substantial revision of all manuscript drafts, and all authors approved the manuscript. 